\title{
Review Article \\ Side Population Cells as Prototype of Chemoresistant, Tumor-Initiating Cells
}

\author{
Vinitha Richard, Madhumathy G. Nair, T. R. Santhosh Kumar, and M. Radhakrishna Pillai \\ Cancer Research Program, Rajiv Gandhi Centre for Biotechnology, Thiruvananthapuram, Kerala 695014, India \\ Correspondence should be addressed to M. Radhakrishna Pillai; mrpillai@rgcb.res.in
}

Received 3 May 2013; Accepted 23 September 2013

Academic Editor: Jiing-Kuan Yee

Copyright ( 2013 Vinitha Richard et al. This is an open access article distributed under the Creative Commons Attribution License, which permits unrestricted use, distribution, and reproduction in any medium, provided the original work is properly cited.

\begin{abstract}
Classically, isolation of CSCs from tumors exploits the detection of cell surface markers associated with normal stem cells. Invariable expression of these cell surface markers in almost all proliferating tumor cells that albeit impart specific functionality, the universality, and clinical credibility of CSC phenotype based on markers is still dubious. Side Population (SP) cells, as defined by Hoechst dye exclusion in flow cytometry, have been identified in many solid tumors and cell lines and the SP phenotype can be considered as an enriched source of stem cells as well as an alternative source for the isolation of cancer stem cells especially when molecular markers for stem cells are unknown. SP cells may be responsible for the maintenance and propagation of tumors and the proportion of SP cells may be a predictor of patient outcome. Several of these markers used in cell sorting have emerged as prognostic markers of disease progression though it is seen that the development of new CSC-targeted strategies is often hindered by poor understanding of their regulatory networks and functions. This review intends to appraise the experimental progress towards enhanced isolation and drug screening based on property of acquired chemoresistance of cancer stem cells.
\end{abstract}

\section{Introduction}

The fundamental problem of tumor recurrence and failing conventional therapies is largely due to the continuing presumption that human cancer cell populations are homogeneous and every cell in a tumor has indistinguishable tumorigenic potential. Recent experiments, however, insinuate that human tumors may not in fact be functionally homogeneous but comprise of a very small fraction of cells that possess actual tumorigenic potential $[1,2]$. This scenario subsequently led to the postulation of the cancer stem cell hypothesis which puts forth that cancer cells have an hierarchical developmental structure in which only a fraction of cells termed cancer stem cells (CSCs) can proliferate indefinitely and form tumors [3]. One of the great advantages of the cancer stem cell hypothesis is that it also helps in understanding other cancer concepts such as minimal residual disease [4]. Cancers that follow the CSC model may as well undergo clonal evolution if more than one type of CSCs coexist or CSCs are under environmental selection [5]. Furthermore, series of genetic mutations impart one or another type of growth advantage instigating Darwinian evolution and survival of a group of stronger stem-like cancer cells overruling translation to malignancy [6]. Evidence that either stem or progenitor cells can act as targets for tumor initiation in a range of solid tumors have been exclusively reviewed by Visvader [7]. Substantiation of this hypothesis has gradually gathered pace over the past few years opening up the reality that design of current treatment strategies may have overlooked these pivotal cells and their molecular networks that hold the key to tumor recurrence and relapse.

Understanding the molecular and cellular basis of tumor heterogeneity both in hematological and solid malignancies and related treatment resilience requires accurate discrimination of tumor propagating stem-like cells from the nonmalignant cells. This review focuses on the experimental advances made in the direction of uncovering CSCs in multiple tumor types and elucidates their role in enhanced chemo-resistance and metastatic potentials. We also discuss herein the major regulatory networks governing CSCmediated chemoresistance and CSC-based drug screening assays leading to effective futuristic modes of therapeutic interventions. 


\section{Proof of CSC Concept-The Assays}

Self-renewal and lineage capacity are the hallmarks of any stem cell. Therefore, as with normal stem cells, assays for cancer stem cell activity need to be evaluated for their potential to show both self-renewal and tumor propagation. Prospective isolations of CSC allow their direct comparison to normal stem/progenitors, revealing important information about CSC regulation, CSC origins, and disease pathogenesis. Purification of solid tumor-initiating cells (T-IC) has been difficult because of the universal expression pattern of most cell surface markers that are currently selected for cell sorting [8]. T-IC xenograft assays for primary human solid tumor tissue in nude mice pose the challenge of residual immune function, triggering host resistance mechanisms that will not permit single T-IC to be detected [9]. Xenotransplantation systems only measure the ability of a human tumor cell to grow in a permissive mouse niche and do not reflect the actual intrinsic behaviour in vivo. At present, there is no superior assay system to measure the tumorigenic potential of primary human tumor isolates $[3,10]$.

An ideal in vitro assay would be (a) quantitative, (b) highly specific and sensitive to detect CSCs even at low frequency, and (c) rapid. Several in vitro assays have been used to identify tumor stem cells, including sphere assays, serial colony-forming unit (CFU) assays (replating assays), and label-retention assays [3]. Expression of surface markers by CSCs may vary over time and/or by location [11]. Isolation of CSCs was based on functional activity when CSC cell surface phenotypes could not be applied to all cancers arising from the same tissue type. Investigators have FACS-purified and functionally characterized human cancers based on aldehyde dehydrogenase (ALDH) expression, demonstrating that ALDH+ cells are enriched for CSCs in primary breast [12] and colon cancer [13]. In some cases, markers not previously identified on normal stem/progenitors have been used to isolate tumorigenic populations. ABCB5, a known chemoresistance mediator in melanoma, was expressed in only a minority of tumor cells (1.6-20.4\%) and only ABCB5+ cells were capable of establishing primary grafts and serially transplanting disease in NOD/SCID mice [14].

An early method for stem cell isolation used the drug efflux property of stem cells. Most cells accumulate fluorescent dyes such as Hoechst 33342 and Rhodamine, but a subset of "dull cells" is often found and termed the "side population" (SP phenotype) (Figure 1). A large fraction of hematopoietic stem and tissue stem cells is in the SP fraction, and most of the cells in the SP fraction are stem cells (extensively reviewed in [15]). These cells maintain a high efflux capability for antimitotic drugs as well. The method was first described in murine bone marrow cells while displaying Hoechst fluorescence simultaneously at two emission wavelengths, wherein SP cells represented a small subset of cells that were enriched at least 1000-fold in HSC activity [16]. SP cells isolated from malignant gastric [17] and gallbladder carcinoma [18] cells have been shown to exhibit stem cell characteristics such as unlimited self-renewal, multipotent potential, and drug resistance [3].
The SP cells are identified according to their ability to efflux the Hoechst dye at a higher pace than the remaining tumor cells termed the main population (non-SP). Moreover, the degree of efflux activity seems to correlate with the maturation state, such that cells displaying highest efflux activity are the most primitive in terms of differentiation potential. There is also a direct link between dye efflux and stem cell capacity, such that the cells at the lowest tip of SP phenotype (with the highest dye efflux and least amount of dye) exhibited the highest stem cell activity over the longest period of time [16]. T-ICs sorted in this method displayed self renewal capabilities in vivo; that is, the sorted cells generated a tumor mass in mice every time they were transplanted into a new mouse [19]. However, as with cell surface markers, possession of an SP phenotype is not a universal property of stem cells, and in some tissues, the SP fraction may not contain the stem cells. Indeed, combining SP determination with cell-surface marker phenotyping has lead to efficient and reliable characterization of one of the most pure and potent adult stem cell populations, the HSC subset. The SP assay has finally emerged as a promising method for identifying stem cell and progenitor populations in different tissues (Table 1), particularly in the absence of specific cell-surface markers [20].

\section{Regulators of Multidrug Resistance in CSCs}

In clinical scenario, many patients with solid tumors respond poorly to existing treatment regimens (including chemotherapy, radiation, and tumor-targeted agents) or relapse quickly after an initial remission. Several characteristics that make CSCs resistant to conventional chemo- and radiotherapy include high expression of drug transporters, relative cell cycle quiescence, high levels of DNA repair machinery, and resistance to apoptosis [15]. The potential for quiescence of cancer stem cells is also a potential concern, and these cells may be resistant to drugs even in the absence of transporter expression or activity. The nature of clinical drug resistance is multifactorial, involving alteration in drug targets, inactivation/detoxification of the drug, decreased drug uptake, increased drug efflux, and the dysregulation of apoptotic pathways [21]. ABC transporters are not the sole cause of drug resistance in CSCs; several other factors (Figure 2), such as the capacity of a stem cell for DNA repair and its quiescent state, may also have an impact on drug resistance in a tumor [22].

3.1. Drug Transporters. Amongst the three "ATP-binding cassette (ABC)" transporters ABCB1 (MDR1/P-glycoprotein), $A B C C 1$, and $A B C G 2,(B C R P)$ had the highest expression in side population (SP) cells [23]. ABCG2 emerged as an important multidrug resistance protein because it confers cross-resistance to several structurally unrelated classes of cancer chemotherapeutic agents [24]. A recent discovery showed that Nrf2, an oxidative stress sensor, maintains the SP cell phenotype by upregulating ABCG2 expression through its direct interaction with an antioxidant response element [ARE] on the ABCG2 promoter [25]. The functional MDR1 conferred resistance to apoptosis induced by 


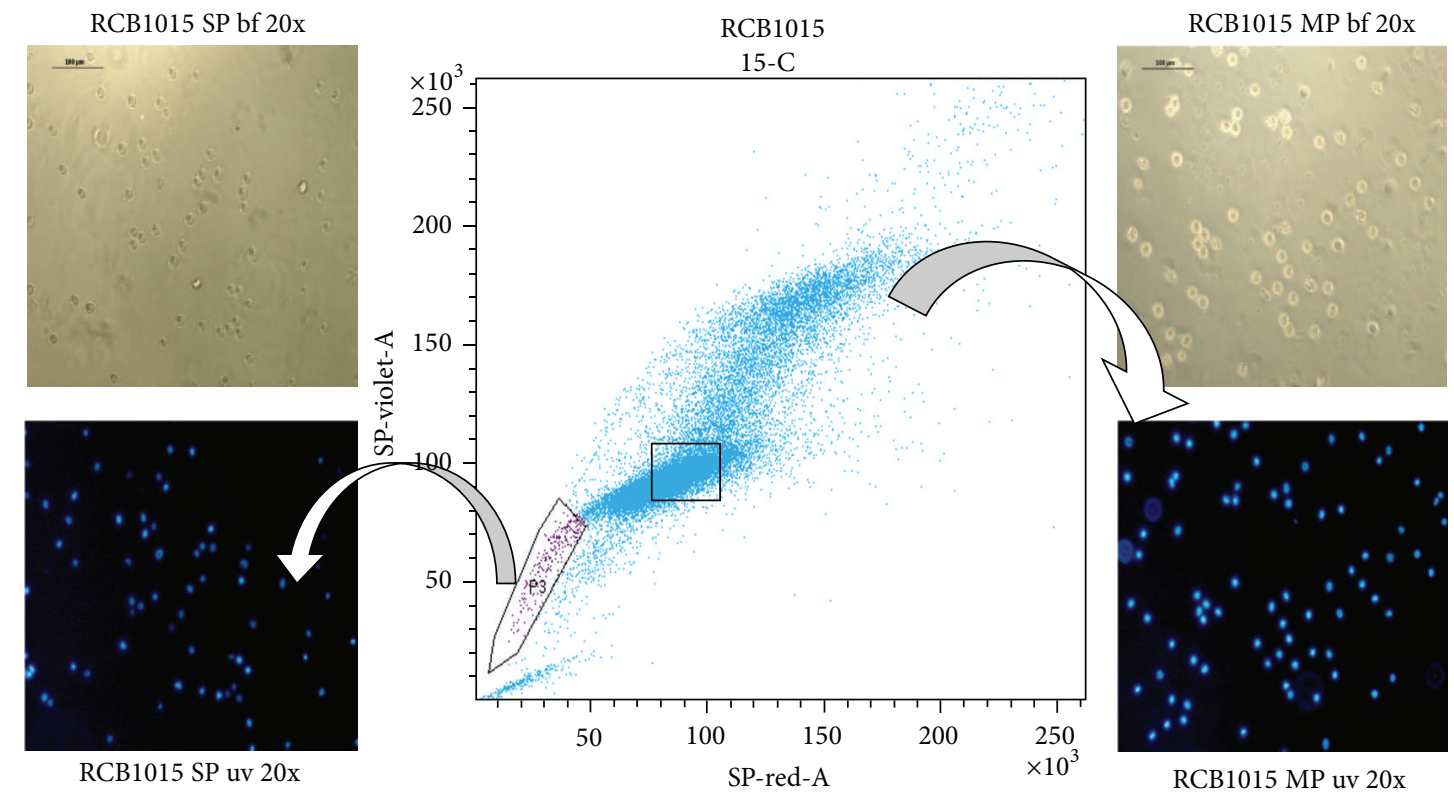

FIGURE 1: "Side population" phenotype in an oral squamous cell carcinoma cell line, RCB1015. The cell line was stained with Hoechst33342 and analyzed by flow cytometry. (SP-side population; MP-main population; bf-bright field image; uv-ultraviolet fluorescence; blue color- nuclear staining with Hoechst33342 dye).

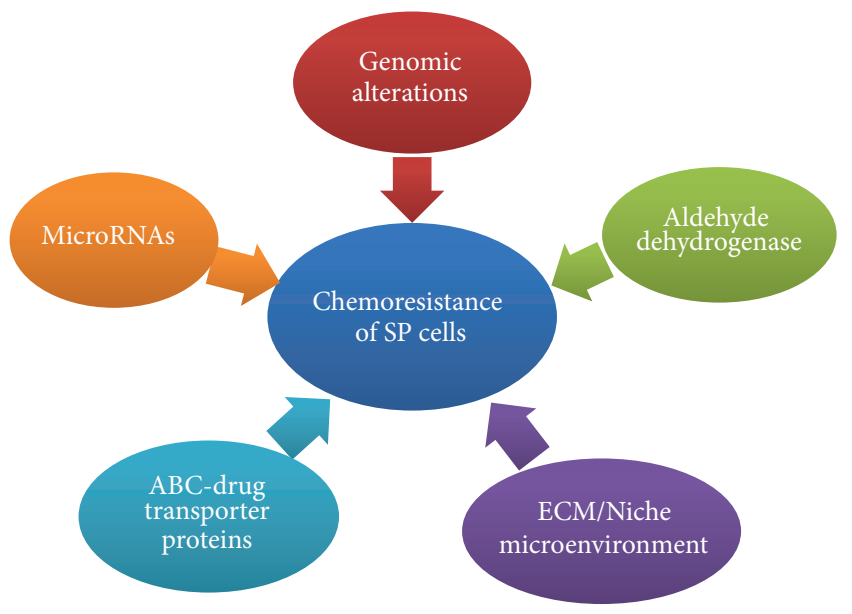

FIgURE 2: Prime instigators for chemoresistance in tumor stem cells. Factors contributing to acquired chemoresistance in cancer stem cells epitomized by side population phenotype across multiple tumor types.

chemotherapeutic drugs in addition to a fundamental role in regulating cell death mediated by caspases. MDR1 has also been shown to confer resistance to cell lysis induced by activated complements [26]. This growing body of evidence implicates the importance of transporter proteins in the protection of the SP cells against a diverse range of cell death stimuli by functioning as an energy-dependent pump, which exports drugs out of drug-resistant mammalian cells, lowering the intracellular drug concentration to sublethal levels, thus acting as determinants of the chemoresistant phenotype of stem-like SP cells in several human malignancies. They also impart resistance to multiple chemotherapeutic drugs currently used in therapy (Table 2).

3.2. Genomic Instability. Cancers in general exhibit extensive modifications in genome composition, ranging from subtle point mutations to dramatic gains and loss of genetic material (aneuploidy) [27]. The vast majority are likely to be passenger mutations [somatic mutations without functional consequences] that do not contribute to the development of cancer or confer any clonal growth advantage that often occur during cell division [28]. However, a small minority are critical drivers of tumorigenesis that would have occurred during growth of the cancer, conferring a growth advantage by positively selecting cancer cells in the microenvironment of tissue origin [28]. These alterations also render tumor cells the ability to evade growth-inhibitory signals, resulting in uncontrolled tumor growth. To affirm that genomic instability is involved in the induction of CSCs, studies have been conducted using side population (SP) cells in human nasopharyngeal carcinoma [NPC CNE-2] and CD133+ human neuroblastoma cells [29]. These cells were subjected to DNA damage by ultraviolet light and mitomycin $\mathrm{C}$ treatment resulting in an increase in SP fraction with overexpression of cell cycle regulators in NPC and neuroblastoma SKN-SH cells. An increase in the number of SP cells was also observed in recurrent tumor tissue as compared with the primary tumor in the same NPC patient [29]. Studies mention that DNA methylation could also be one of the reasons for acquired drug resistance. A total of 13/41 genes were consistently hypermethylated in cisplatinresistant ovarian cancer cell line A2780 cell derivatives. Furthermore, 5/13 genes [ARMCX2, COL1A1, MDK, MEST, 
TABLE 1: An account of stem cell-like SP phenotype in malignancies.

\begin{tabular}{|c|c|c|c|}
\hline Tumor type & $(\%)$ of sp cells & Cellular phenotype and features of sp cells & Ref. \\
\hline Breast & $0.18 \pm 0.45 \%$ & $\begin{array}{l}\text { CD44+/CD24-/vimentin higher and lower levels of } \\
\text { cytokeratins compared to non-SP cells. }\end{array}$ & $\begin{array}{l}{[53]} \\
{[54]}\end{array}$ \\
\hline Lung adenocarcinoma & $24 \%$ & $\begin{array}{l}\text { SP cells showed chemoresistance to platinum drugs and high } \\
\text { expression of genes related to drug resistance (AKR1C1/C2 and } \\
\text { NR0B1) or cancer metastasis (TM4SF1) \& high mRNA } \\
\text { expression of ABCG2, ABCC2. }\end{array}$ & {$[55]$} \\
\hline Endometrial cancer & $0.02 \%$ & $\begin{array}{l}\text { Higher expression levels of vimentin, alpha-smooth muscle } \\
\text { actin, and collagen III in SP induced tumors. }\end{array}$ & {$[56,57]$} \\
\hline Ewing's sarcoma & $1.2 \%$ & $\begin{array}{l}\text { High clonogenicity, invasiveness, and ABC transporter } \\
\text { expression in SP cells than non-SP }\end{array}$ & {$[58]$} \\
\hline Glioblastoma & $0.4-1.5 \%$ & $\begin{array}{l}\text { CD133+ SP cells coexpressed nestin and generated tumors in } \\
\text { brains of NOD/SCID mice. }\end{array}$ & [59] \\
\hline Prostate cancer & $0.1-0.9 \%$ & $\begin{array}{l}\text { CD133+, CD45-, CD81+, Sca-1+ } \\
\text { SP clonal cells secreted (TGF-beta1) }\end{array}$ & {$[60]$} \\
\hline Pancreatic cancer & $2.1-8.7 \%$ & $\begin{array}{l}\text { CD133+ SP cells showed significant levels of mRNA expression } \\
\text { for CD133, ABCG2, and Notch1 than non-SP cells. }\end{array}$ & {$[61]$} \\
\hline Leukemia & $0.008-4.1 \%$ & CD34(+) CD38(-) CD123+ & {$[62]$} \\
\hline Hepatocellular carcinoma & $0.1-28.7 \%$ & $\begin{array}{l}\text { SP cells showed high chemoresistance, self-renewal, } \\
\text { clonogenicity, and ABCG2 expression. }\end{array}$ & {$[63]$} \\
\hline Medulloblastoma & $12.4-39.1 \%$ & $\begin{array}{l}\text { CD133+ SP cells with increased cell size, decreased S-phase, and } \\
\text { proliferative capacity. }\end{array}$ & {$[64]$} \\
\hline Renal epithelial malignancy & $5.9 \pm 0.9 \%$ & $\begin{array}{l}\text { SP enriched for quiescent cells with high proliferative capacity } \\
\text { and stem-like properties. }\end{array}$ & {$[65]$} \\
\hline Head \& neck squamous Carcinoma & $0.69-0.9 \%$ & $\begin{array}{l}\text { Activation of EGFR, a gene implicated in HNSCC tumorigenesis } \\
\text { leads to increased SP. }\end{array}$ & {$[32]$} \\
\hline Urological malignancy & $0.1-0.6 \%$ & $\begin{array}{l}\text { SP fraction has enhanced colony forming and proliferative } \\
\text { capacity. }\end{array}$ & {$[66]$} \\
\hline Ovarian cancer & $0.9 \%$ & $\begin{array}{l}\text { SP cells showed higher levels of Oct } 3 / 4 \text { and colony formation } \\
\text { efficiency than non-SP cells. }\end{array}$ & {$[67]$} \\
\hline Nasopharyngeal carcinoma & $2.6 \%$ & $\begin{array}{l}\text { CK19 highly expressed SP cells were more chemo/radiation } \\
\text { resistant related to the expression of ABCG } 2 / \text { smoothened } \\
\text { protein. }\end{array}$ & {$[68]$} \\
\hline Melanoma & $0.96 \%$ & CD44+/CD133+/CD24+/ABCG2 high SP cells. & {$[69]$} \\
\hline Laryngeal cancer & $1.7-17 \%$ & $\begin{array}{l}\text { SP cells had high self-renewal, proliferation, radiation } \\
\text { resistance, and tumorigenicity. }\end{array}$ & {$[70]$} \\
\hline Gastric cancer & $0.001-12 \%$ & $\begin{array}{l}\text { High expression levels of adhesion molecules } \alpha 2, \alpha 5, \beta 3 \text { and } \beta 5 \\
\text { integrins, CD } 44 \text {, Oct } 3 / 4 \text {, and Sox } 2 \text { in SP cell-injected tumors. }\end{array}$ & {$[71]$} \\
\hline
\end{tabular}

and MLH1] acquired methylation in SP cells isolated from drug-resistant ovarian cancer [30].

3.3. Signalling Pathways. Expression of EGFR and other erbB receptors are deregulated in many cancers [31] and a study on head and neck squamous cell carcinoma cell lines showed that activation of EGFR leads to increase in chemoresistant fraction of SP cells thereby playing a role in regulating cancer stem cells and tumorigenesis in such tumors [32]. IRESSA [Gefitinib-EGFR inhibitor] plus Vincristine treatment led to impairment of SP phenotype [32]. PI3K pathway is also said to be involved in regulating the SP phenotype.
Recently, it was shown that a PI3K inhibitor LY294002 could inhibit all ABCG2, MDR1, and MRP1, the three classes of ABC transporters that were overexpressed in SP cells and multidrug resistance [33]. Treatment with Hedgehog [Hh] pathway inhibitor Cyclopamine or Cyclopamine and Paclitaxel decreased the SP population and expression levels of MDR1 efflux protein in prostate cancer cell lines [34]. Gene profiling studies and protein profiling have demonstrated an elevated expression of chemoresistance associated proteins in various types of cancers. A recent study on human stage II breast cancer specimens showed an increased expression of Fra-1 a member of the Fos transcription factor family, 
TABLE 2: Multidrug resistance mediated by SP cells.

\begin{tabular}{|c|c|c|}
\hline SP expressing cancers & Resistance to drugs & Ref \\
\hline Gastric cancer cell line SGC-7901 & 5-Fluorouracil cisplatin, 5-fluorouracil, doxorubicin & {$[18,72]$} \\
\hline Melanoma & Paclitaxel & {$[73]$} \\
\hline Malignant pleural mesothelioma & Mitoxantrone & {$[50]$} \\
\hline Head and neck squamous cell carcinoma & 5-Fluorouracil mitoxantrone & {$[74,75]$} \\
\hline CLL & Fludarabine, bendamustine, or rituximab & {$[76]$} \\
\hline Pancreatic carcinoma & Gemcitabine & {$[77,78]$} \\
\hline Nasopharyngeal & Mitoxantrone, cisplatin, mitomycin-C & {$[68]$} \\
\hline Endometrial & Paclitaxel & {$[56]$} \\
\hline Glioma & 5-Fluorouracil and carboplatin & [79] \\
\hline Breast & Paclitaxel, epirubicin, mitoxantrone, carboplatin & $\begin{array}{l}{[80]} \\
{[54]}\end{array}$ \\
\hline Lung & Mitoxantrone, doxorubicin & {$[55]$} \\
\hline Esophageal & 5-Fluorouracil & {$[81]$} \\
\hline Bladder & Mitomycin-C, mitoxantrone & [82] \\
\hline
\end{tabular}

correlated with a reduced side population fraction [35]. The reverse was observed between reduced expression of Fra-1 and chemoresistance [35] which implies the existence of various regulatory proteins that could be tuning the chemoresistant side population cells.

3.4. MicroRNA. Recent researches have shed light on the biological importance of miRNAs in the maintenance of side population phenotype. The mammalian genome encodes hundreds of MicroRNAs [miRNAs] that collectively affect the expression of about one-third of all genes. They are an abundant class of small nonprotein-coding RNAs that function as negative gene regulators. Recent evidence has shown that dysregulation of miRNA activity is associated with disease. miRNAs have been shown to repress the expression of important cancer-related genes and might prove useful in the diagnosis and treatment of cancer. Certain miRNAs have been shown to promote oncogenesis "oncomirs" or to repress it [36]. Recent work by Misawa et al. [37] has highlighted the role of microRNA-21 (miR-21) and its upstream regulator activator protein-I (AP-1) in sustenance of the chemoresistant SP cells. Treatment of the cells with the AP-1 inhibitor SP600125 attenuated miR-21 levels and increased topotecan sensitivity [37]. miR-Let-7 is downregulated in SP cells and the downregulation in turn makes let-7 lose the prospects to restrain Ras mRNA, leading to activation of $\mathrm{p}$-Ras and p-ERK [38]. Upregulation of let-7 also leads to suppression of ER $\alpha$ and may be a promising strategy for the inhibition of the ER signaling pathway and for the elimination of cancer stem cells, thus aiding in the treatment of breast cancer [39]. Recently, miR200c and 34a have also been shown to modulate chemoresistance against Cyclopamine and paclitaxel in prostate cancer cell lines [34]. miR-328 is also important for the maintenance of SP phenotype. miR328 overexpression reversed drug resistance and inhibited cell invasion of SP cells of colorectal cancer [40].

3.5. Aldehyde Dehydrogenase (ALDH). Similar to Hoechst dye extruding SP cells, high expression of ALDH appears to be a marker for stem cells from many tissues [41] and methodology to isolate viable cells by ALDH activity using a fluorescent labeled aldehyde substrate [Aldefluor] is now available. Data from several groups suggest that Hoechst and ALDH may identify SP cells from a variety of malignancies, and combined use of ALDH and Hoechst efflux activity to isolate the quiescent stem cell fractions and may be particularly useful in those malignancies where little is known about the phenotypes associated with the differentiation program of the tissues of origin [42]. The elevated expression of ALDH in side population cells might be playing a role in rendering resistance to chemotherapeutic agents. Aldehyde dehydrogenase is a polymorphic enzyme responsible for the oxidation of aldehydes to carboxylic acids. These genes participate in a wide variety of biological processes including the detoxification of exogenously and endogenously generated aldehydes [43]. In normal stem cells, specifically the ALDH1 family mediates the synthesis of intracellular all-trans-retinoic acid that is required for the growth of the hematopoietic system and other tissues [44]. The role of ALDH is not limited to retinoic acid metabolism, as it is also involved in the detoxification. ALDH1 is cytosolic, ubiquitously distributed, and in particular confers resistance to anticancer drugs of the cyclophosphamide family by their detoxification [44]. ALDH family of enzymes are known markers of chemoresistance as evident from studies done on various types of cancers and tumour initiating cells $[45,46]$. Hence, targeting SP cells should be considered as alternative models for high throughput drug screening that might aid in significantly improving existing therapeutic inconsistencies associated with chemoresistant tumor-initiating cells.

\section{Renewal of Therapeutic Realization}

Identification of cancer stem cells to date is based on tumorigenic potential in permissive conditions and not dependent on the actual fate of cells within patients under specific conditions [47]. Cancer cells with tumorigenic potential 
could be held transiently or permanently, by environmental, epigenetic, or immunological mechanisms from actually contributing to disease as elucidated in CSC shift hypothesis [8, 47]. Agents or compounds that show specific activity against SP cells will have a definite role after primary debulking therapy. Drugs have to be developed to target specifically these SP cells that have higher malignant potential with numerous getaway strategies from immune surveillance and attack ensuing minimal residual disease [MRD], metastasis, and recurrence. Various attempts have been developed in formulating such drugs that would transpire as a promising cure for cancer, particularly in combination with chemotherapy. Salinomycin was found to act as a potent inhibitor of multidrug resistance gp170, as evidenced through drug efflux assays in cancer cell lines overexpressing P-gp/MDR1 [48]. Since SP cells overexpress MDR1 it might serve as a potent inhibitor of SP cells as well. Curcumin has shown to inhibit the side population [SP] cells of rat C6 glioma cell line and is a dietary phytochemical with potential to target stem cell mediated tumor initiation and development [49]. A reactive oxygen species [ROS] generator Emodin (1,3,8-trihydroxy-6methylanthraquinone), suppressed the function of ABCG2 via ROS-related mechanism. Emodin was also able to sensitize SP cells to cisplatin by the inhibition of expression of abcg2 [18]. The PI3K/mTOR inhibitor NVP-BEZ235 and $\mathrm{PI} 3 \mathrm{~K}$ inhibitor Wortmannin were capable of decreasing the SP fraction and the drug efflux along with a significant reduction in the levels of ABCG2 [50]. Low-molecularweight heparin [LMWH] combined with cisplatin could overcome cisplatin-resistance and induced apoptosis in lung SP cells both in vitro and in vivo [51]. Tetrahydrocurcumin (THC), the ultimate metabolite of the curcumins in vivo, was found to be able to inhibit the function of P-gp, MRP1, and MXR and additional evidences also directed towards the development of curcumin I and THC as MDR modulator to use in combination with conventional chemotherapy [52]. Even though several strategies for targeting cancer stem cells have been proposed, a number of concerns related to efficacy and outreach are yet to be explored and resolved before such research targeting cancer stem cells can enter clinical trials.

Further elucidation of the biological features of these putative tumor initiating cells with radical survival capacity and tumorigenic potential may impart new insights on factors that drive sudden acquired drug resistance. This survival tactic of cancer cells has been consistently creating numerous hurdles towards restorative therapy for a number of human malignancies. Better comprehension of the concept and reassessment of existing preclinical drug development paradigms that target the molecular pathways controlling self renewal, survival, and resistance in cancer stem cells can significantly improve existing therapeutic inconsistencies by eliminating both the root and stem of the disease.

\section{Authors' Contribution}

V. Richard and M. G. Nair have contributed equally to this review.

\section{References}

[1] C. A. O'Brien, A. Pollett, S. Gallinger, and J. E. Dick, "A human colon cancer cell capable of initiating tumour growth in immunodeficient mice," Nature, vol. 445, no. 7123, pp. 106-110, 2007.

[2] J. E. Dick, "Stem cell concepts renew cancer research," Blood, vol. 112, no. 13, pp. 4793-4807, 2008.

[3] M. F. Clarke and M. Fuller, "Stem cells and cancer: two faces of eve," Cell, vol. 124, no. 6, pp. 1111-1115, 2006.

[4] Y. Welte, J. Adjaye, H. R. Lehrach, and C. R. A. Regenbrecht, "Cancer stem cells in solid tumors: elusive or illusive?" Cell Communication and Signaling, vol. 8, pp. 6-8, 2010.

[5] L. L. C. Marotta and K. Polyak, "Cancer stem cells: a model in the making," Current Opinion in Genetics and Development, vol. 19, no. 1, pp. 44-50, 2009.

[6] D. Hanahan and R. A. Weinberg, "Hallmarks of cancer: the next generation," Cell, vol. 144, no. 5, pp. 646-674, 2011.

[7] J. E. Visvader, "Cells of origin in cancer," Nature, vol. 469, no. 7330, pp. 314-322, 2011.

[8] V. Richard and M. R. Pillai, “The stem cell code in oral epithelial tumorigenesis: “The cancer stem cell shift hypothesis"', Biochimica et Biophysica Acta, vol. 1806, no. 2, pp. 146-162, 2010.

[9] J. E. Dick, "Breast cancer stem cells revealed," Proceedings of the National Academy of Sciences of the United States of America, vol. 100, no. 7, pp. 3547-3549, 2003.

[10] C. Y. Park, D. Tseng, and I. L. Weissman, "Cancer stem celldirected therapies: recent data from the laboratory and clinic," Molecular Therapy, vol. 17, no. 2, pp. 219-230, 2009.

[11] S. V. Shmelkov, J. M. Butler, A. T. Hooper et al., "CD133 expression is not restricted to stem cells, and both $\mathrm{CD}_{133^{+}}$and CD133- metastatic colon cancer cells initiate tumors," Journal of Clinical Investigation, vol. 118, no. 6, pp. 2111-2120, 2008.

[12] C. Ginestier, M. H. Hur, E. Charafe-Jauffret et al., "ALDH1 is a marker of normal and malignant human mammary stem cells and a predictor of poor clinical outcome," Cell Stem Cell, vol. 1, no. 5, pp. 555-567, 2007.

[13] S. J. Dylla, L. Beviglia, I.-K. Park et al., "Colorectal cancer stem cells are enriched in xenogeneic tumors following chemotherapy," PLoS ONE, vol. 3, no. 6, Article ID e2428, 2008.

[14] T. Schatton, G. F. Murphy, N. Y. Frank et al., "Identification of cells initiating human melanomas," Nature, vol. 451, no. 7176, pp. 345-349, 2008.

[15] M. Dean, "ABC transporters, drug resistance, and cancer stem cells," Journal of Mammary Gland Biology and Neoplasia, vol. 14, no. 1, pp. 3-9, 2009.

[16] M. A. Goodell, M. Rosenzweig, H. Kim et al., "Dye efflux studies suggest that hematopoietic stem cells expressing low or undetectable levels of CD34 antigen exist in multiple species," Nature Medicine, vol. 3, no. 12, pp. 1337-1345, 1997.

[17] R. Li, X. Wu, H. Wei, and S. Tian, "Characterization of side population cells isolated from the gastric cancer cell line SGC7901," Oncology Letters, vol. 5, pp. 877-883, 2013.

[18] X. X. Li, Y. Dong, W. Wang et al., "Emodin as an effective agent in targeting cancer stem-like side population cells of gallbladder carcinoma," Stem Cells and Development, vol. 22, pp. 554-566, 2013.

[19] R. P. Hill and R. Perris, “Destemming' cancer stem cells," Journal of the National Cancer Institute, vol. 99, no. 19, pp. 14351440, 2007. 
[20] A. Golebiewska, N. H. C. Brons, R. Bjerkvig, and S. P. Niclou, "Critical appraisal of the side population assay in stem cell and cancer stem cell research," Cell Stem Cell, vol. 8, no. 2, pp. 136147, 2011.

[21] M. M. Gottesman, T. Fojo, and S. E. Bates, "Multidrug resistance in cancer: role of ATP-dependent transporters," Nature Reviews Cancer, vol. 2, no. 1, pp. 48-58, 2002.

[22] K. Moitra, H. Lou, and M. Dean, "Multidrug efflux pumps and cancer stem cells: insights into multidrug resistance and therapeutic development," Clinical Pharmacology and Therapeutics, vol. 89, no. 4, pp. 491-502, 2011.

[23] R. Katayama, S. Koike, S. Sato, Y. Sugimoto, T. Tsuruo, and N. Fujita, "Dofequidar fumarate sensitizes cancer stem-like side population cells to chemotherapeutic drugs by inhibiting ABCG2/BCRP-mediated drug export," Cancer Science, vol. 100, no. 11, pp. 2060-2068, 2009.

[24] N. Chikazawa, H. Tanaka, T. Tasaka et al., "Inhibition of Wnt signaling pathway decreases chemotherapy-resistant sidepopulation colon cancer cells," Anticancer Research, vol. 30, no. 6, pp. 2041-2048, 2010.

[25] A. Singh, H. Wu, P. Zhang, C. Happel, J. Ma, and S. Biswal, "Expression of ABCG2 (BCRP) is regulated by Nrf2 in cancer cells that confers side population and chemoresistance phenotype," Molecular Cancer Therapeutics, vol. 9, no. 8, pp. 23652376, 2010.

[26] G. A. Challen and M. H. Little, "A side order of stem cells: the SP phenotype," Stem Cells, vol. 24, no. 1, pp. 3-12, 2006.

[27] G. Pihan and S. J. Doxsey, "Mutations and aneuploidy: coconspirators in cancer?" Cancer Cell, vol. 4, no. 2, pp. 89-94, 2003.

[28] M. R. Stratton, P. J. Campbell, and P. A. Futreal, "The cancer genome," Nature, vol. 458, no. 7239, pp. 719-724, 2009.

[29] Y. Liang, Z. Zhong, Y. Huang et al., "Stem-like cancer cells are inducible by increasing genomic instability in cancer cells," Journal of Biological Chemistry, vol. 285, no. 7, pp. 4931-4940, 2010.

[30] C. Zeller, W. Dai, N. L. Steele et al., "Candidate DNA methylation drivers of acquired cisplatin resistance in ovarian cancer identified by methylome and expression profiling," Oncogene, vol. 31, pp. 4567-4576, 2012.

[31] R. Roskoski Jr., "The ErbB/HER receptor protein-tyrosine kinases and cancer," Biochemical and Biophysical Research Communications, vol. 319, no. 1, pp. 1-11, 2004.

[32] J. S. Chen, F. S. Pardo, J. Wang-Rodriguez et al., "EGFR regulates the side population in head and neck squamous cell carcinoma," Laryngoscope, vol. 116, no. 3, pp. 401-406, 2006.

[33] Y. Imai, H. Yamagishi, Y. Ono, and Y. Ueda, "Versatile inhibitory effects of the flavonoid-derived PI3K/Akt inhibitor, LY294002, on ATP-binding cassette transporters that characterize stem cells," Clinical and Translational Medicine, vol. 1, article 24, 2012.

[34] S. Singh, D. Chitkara et al., "Chemoresistance in prostate cancer cells is regulated by miRNAs and Hedgehog pathway," PLoS ONE, vol. 7, Article ID e40021, 2012.

[35] D. Lu, S. Chen, X. Tan et al., "Fra-1 promotes breast cancer chemosensitivity by driving cancer stem cells from dormancy," Cancer Research, vol. 72, no. 14, pp. 3451-3456, 2012.

[36] S. F. Tavazoie, C. Alarcón, T. Oskarsson et al., "Endogenous human microRNAs that suppress breast cancer metastasis," Nature, vol. 451, no. 7175, pp. 147-152, 2008.

[37] A. Misawa, R. Katayama, S. Koike, A. Tomida, T. Watanabe, and N. Fujita, "AP-1-dependent miR-21 expression contributes to chemoresistance in cancer stem cell-like SP cells," Oncology Research, vol. 19, no. 1, pp. 23-33, 2010.

[38] X. Sun, C. Fan, L. J. Hu, N. Du, C. W. Xu, and H. Ren, "Role of let-7 in maintaining characteristics of breast cancer stem cells," Xi Bao Yu Fen Zi Mian Yi Xue Za Zhi, vol. 28, no. 8, pp. 789-792, 2012.

[39] X. Sun, S. Qin, C. Fan et al., "Let-7: a regulator of the ERalpha signaling pathway in human breast tumors and breast cancer stem cells," Oncology Reports, vol. 29, pp. 2079-2087, 2013.

[40] X. T. Xu, Q. Xu, J. L. Tong et al., "MicroRNA expression profiling identifies miR-328 regulates cancer stem cell-like SP cells in colorectal cancer," British Journal of Cancer, vol. 106, no. 7, pp. 1320-1330, 2012.

[41] G. Zhang, L. Ma, Y. K. Xie, X. B. Miao, and C. Jin, "Esophageal cancer tumorspheres involve cancer stem-like populations with elevated aldehyde dehydrogenase enzymatic activity," Molecular Medicine Reports, vol. 6, no. 3, pp. 519-524, 2012.

[42] R. J. Jones, J. P. Barber, M. S. Vala et al., "Assessment of aldehyde dehydrogenase in viable cells," Blood, vol. 85 , no. 10, pp. $2742-$ 2746, 1995.

[43] D. W. Crabb, M. Matsumoto, D. Chang, and M. You, "Overview of the role of alcohol dehydrogenase and aldehyde dehydrogenase and their variants in the genesis of alcohol-related pathology," Proceedings of the Nutrition Society, vol. 63, no. 1, pp. 49-63, 2004.

[44] J. Hilton, "Role of aldehyde dehydrogenase in cyclophosphamide-resistant L1210 leukemia," Cancer Research, vol. 44, no. 11, pp. 5156-5160, 1984.

[45] C. P. Huang, M. F. Tsai, T. H. Chang et al., "ALDH-positive lung cancer stem cells confer resistance to epidermal growth factor receptor tyrosine kinase inhibitors," Cancer Letters, vol. 328, no. 1, pp. 144-151, 2013.

[46] A. Schafer, J. Teufel, F. Ringel et al., "Aldehyde dehydrogenase 1A1-a new mediator of resistance to temozolomide in glioblastoma," Neuro-Oncology, vol. 14, no. 12, pp. 1452-1464, 2012.

[47] M. Shackleton, E. Quintana, E. R. Fearon, and S. J. Morrison, "Heterogeneity in cancer: cancer stem cells versus clonal evolution," Cell, vol. 138, no. 5, pp. 822-829, 2009.

[48] R. Riccioni, M. L. Dupuis, M. Bernabei et al., "The cancer stem cell selective inhibitor salinomycin is a p-glycoprotein inhibitor," Blood Cells, Molecules, and Diseases, vol. 45, no. 1, pp. $86-92,2010$.

[49] D. Fong, A. Yeh, R. Naftalovich, T. H. Choi, and M. M. Chan, "Curcumin inhibits the side population (SP) phenotype of the rat C6 glioma cell line: towards targeting of cancer stem cells with phytochemicals," Cancer Letters, vol. 293, no. 1, pp. 65-72, 2010.

[50] B. Fischer, C. Frei, U. Moura, R. Stahel, and E. FelleyBosco, "Inhibition of phosphoinositide-3 kinase pathway down regulates ABCG2 function and sensitizes malignant pleural mesothelioma to chemotherapy," Lung Cancer, vol. 78, no. 1, pp. 23-29, 2012.

[51] Q. Niu, W. Wang et al., "Low molecular weight heparin ablates lung cancer cisplatin-resistance by inducing proteasomemediated ABCG2 protein degradation," PLoS ONE, vol. 7, no. 7, Article ID e41035, 2012.

[52] P. Limtrakul, W. Chearwae, S. Shukla, C. Phisalphong, and S. V. Ambudkar, "Modulation of function of three ABC drug transporters, $\mathrm{P}$-glycoprotein (ABCB1), mitoxantrone resistance protein $(\mathrm{ABCG} 2)$ and multidrug resistance protein 1 (ABCC1) by tetrahydrocurcumin, a major metabolite of curcumin," 
Molecular and Cellular Biochemistry, vol. 296, no. 1-2, pp. 8595, 2007.

[53] A. J. Alvi, H. Clayton, C. Joshi et al., "Functional and molecular characterisation of mammary side population cells," Breast Cancer Research, vol. 5, no. 1, pp. R1-R8, 2003.

[54] H. Z. Li, T. B. Yi, and Z. Y. Wu, "Suspension culture combined with chemotherapeutic agents for sorting of breast cancer stem cells," BMC Cancer, vol. 8, pp. 1471-2407, 2008.

[55] J.-M. Sung, H.-J. Cho, H. Yi et al., "Characterization of a stem cell population in lung cancer A549 cells," Biochemical and Biophysical Research Communications, vol. 371, no. 1, pp. 163$167,2008$.

[56] A. M. Friel, P. A. Sergent, C. Patnaude et al., "Functional analyses of the cancer stem cell-like properties of human endometrial tumor initiating cells," Cell Cycle, vol. 7, no. 2, pp. 242-249, 2008.

[57] K. Kato, T. Takao, A. Kuboyama et al., "Endometrial cancer sidepopulation cells show prominent migration and have a potential to differentiate into the mesenchymal cell lineage," American Journal of Pathology, vol. 176, no. 1, pp. 381-392, 2010.

[58] M. Yang, R. Zhang, M. Yan, Z. Ye, W. Liang, and Z. Luo, "Detection and characterization of side population in Ewing's sarcoma SK-ES-1 cells in vitro," Biochemical and Biophysical Research Communications, vol. 391, no. 1, pp. 1062-1066, 2010.

[59] R. Fukaya, S. Ohta, M. Yamaguchi et al., "Isolation of cancer stem-like cells from a side population of a human glioblastoma cell line, SK-MG-1," Cancer Letters, vol. 291, no. 2, pp. 150-157, 2010.

[60] A. Santamaria-Martínez, J. Barquinero, A. Barbosa-Desongles et al., "Identification of multipotent mesenchymal stromal cells in the reactive stroma of a prostate cancer xenograft by side population analysis," Experimental Cell Research, vol. 315, no. 17, pp. 3004-3013, 2009.

[61] Y. H. Wang, F. Li, B. Luo et al., "A side population of cells from a human pancreatic carcinoma cell line harbors cancer stem cell characteristics," Neoplasma, vol. 56, no. 5, pp. 371-378, 2009.

[62] B. Moshaver, A. van Rhenen, A. Kelder et al., "Identification of a small subpopulation of candidate leukemia-initiating cells in the side population of patients with acute myeloid leukemia," Stem Cells, vol. 26, no. 12, pp. 3059-3067, 2008.

[63] G.-M. Shi, Y. Xu, J. Fan et al., "Identification of side population cells in human hepatocellular carcinoma cell lines with stepwise metastatic potentials," Journal of Cancer Research and Clinical Oncology, vol. 134, no. 11, pp. 1155-1163, 2008.

[64] V. K. Srivastava and J. Nalbantoglu, "Flow cytometric characterization of the DAOY medulloblastoma cell line for the cancer stem-like phenotype," Cytometry A, vol. 73, no. 10, pp. 940-948, 2008.

[65] S. K. Addla, M. D. Brown, C. A. Hart, V. A. C. Ramani, and N. W. Clarke, "Characterization of the Hoechst 33342 side population from normal and malignant human renal epithelial cells," American Journal of Physiology, vol. 295, no. 3, pp. F680F687, 2008 .

[66] J. E. Oates, B. R. Grey, S. K. Addla et al., "Hoechst 33342 side population identification is a conserved and unified mechanism in urological cancers," Stem Cells and Development, vol. 18, no. 10, pp. 1515-1521, 2009.

[67] Q. Gao, L. Geng, G. Kvalheim, G. Gaudernack, and Z. Suo, "Identification of cancer stem-like side population cells in ovarian cancer cell line OVCAR-3," Ultrastructural Pathology, vol. 33, no. 4, pp. 175-181, 2009.
[68] J. Wang, L.-P. Guo, L.-Z. Chen, Y.-X. Zeng, and H. L. Shih, "Identification of cancer stem cell-like side population cells in human nasopharyngeal carcinoma cell line," Cancer Research, vol. 67, no. 8, pp. 3716-3724, 2007.

[69] J. Dou, P. Wen, W. Hu et al., "Identifying tumor stem-like cells in mouse melanoma cell lines by analyzing the characteristics of side population cells," Cell Biology International, vol. 33, no. 8, pp. 807-815, 2009.

[70] G. Wan, L. Zhou, M. Xie, H. Chen, and J. Tian, "Characterization of side population cells from laryngeal cancer cell lines," Head and Neck, vol. 32, no. 10, pp. 1302-1309, 2010.

[71] M. Yashiro, K. Yasuda, T. Nishii et al., "Epigenetic regulation of the embryonic oncogene ERas in gastric cancer cells," International Journal of Oncology, vol. 35, no. 5, pp. 997-1003, 2009.

[72] K. Fukuda, Y. Saikawa, M. Ohashi et al., "Tumor initiating potential of side population cells in human gastric cancer," International Journal of Oncology, vol. 34, no. 5, pp. 1201-1207, 2009.

[73] Y. Luo, L. Z. Ellis, K. Dallaglio et al., "Side population cells from human melanoma tumors reveal diverse mechanisms for chemoresistance," Journal of Investigative Dermatology, vol. 132, no. 10, pp. 2440-2450, 2012.

[74] M. R. Loebinger, A. Giangreco, K. R. Groot et al., "Squamous cell cancers contain a side population of stem-like cells that are made chemosensitive by ABC transporter blockade," British Journal of Cancer, vol. 98, no. 2, pp. 380-387, 2008.

[75] S. Yanamoto, G. Kawasaki, S.-I. Yamada et al., "Isolation and characterization of cancer stem-like side population cells in human oral cancer cells," Oral Oncology, vol. 47, no. 9, pp. 855860, 2011.

[76] E. Gross, F.-E. Lfaqihi-Olive, L. Ysebaert et al., "B-chronic lymphocytic leukemia chemoresistance involves innate and acquired leukemic side population cells," Leukemia, vol. 24, no. 11, pp. 1885-1892, 2010.

[77] S.-N. Zhang, F.-T. Huang, Y.-J. Huang, W. Zhong, and Z. Yu, "Characterization of a cancer stem cell-like side population derived from human pancreatic adenocarcinoma cells," Tumori, vol. 96, no. 6, pp. 985-992, 2010.

[78] J. Zhou, C.-Y. Wang, T. Liu et al., "Persistence of side population cells with high drug efflux capacity in pancreatic cancer," World Journal of Gastroenterology, vol. 14, no. 6, pp. 925-930, 2008.

[79] A.-M. Bleau, D. Hambardzumyan, T. Ozawa et al., "PTEN/PI3K/Akt pathway regulates the side population phenotype and ABCG2 activity in glioma tumor stem-like cells," Cell Stem Cell, vol. 4, no. 3, pp. 226-235, 2009.

[80] J. Zhou, J. Wulfkuhle, H. Zhang et al., "Activation of the PTEN/mTOR/STAT3 pathway in breast cancer stem-like cells is required for viability and maintenance," Proceedings of the National Academy of Sciences of the United States of America, vol. 104, pp. 16158-16163, 2007.

[81] D. Huang, Q. Gao, L. Guo et al., "Isolation and identification of cancer stem-like cells in esophageal carcinoma cell lines," Stem Cells and Development, vol. 18, no. 3, pp. 465-473, 2009.

[82] Z.-F. Ning, Y.-J. Huang, T.-X. Lin et al., "Subpopulations of stem-like cells in side population cells from the human bladder transitional cell cancer cell line T24," Journal of International Medical Research, vol. 37, no. 3, pp. 621-630, 2009. 


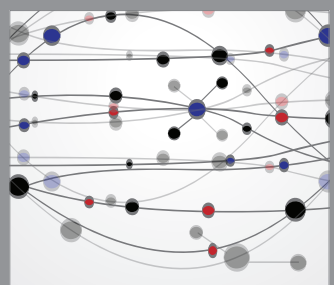

The Scientific World Journal
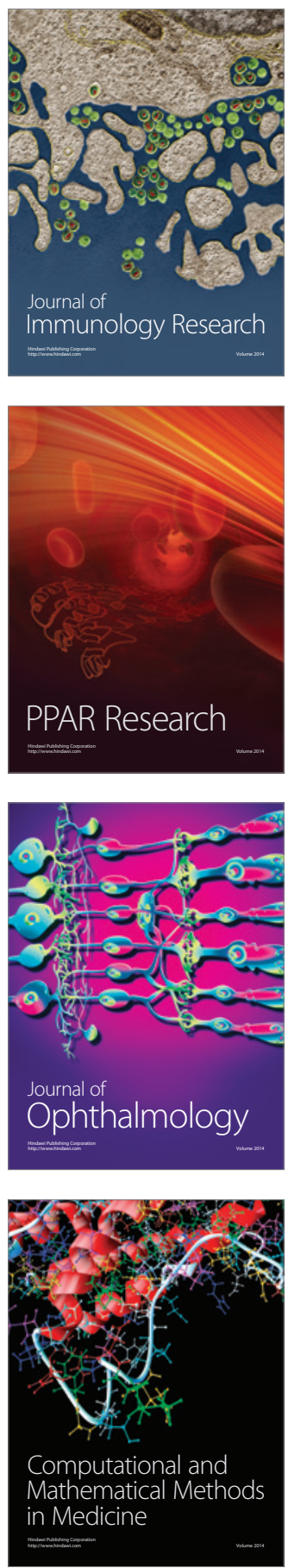

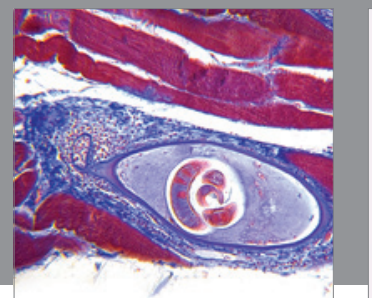

Gastroenterology

Research and Practice
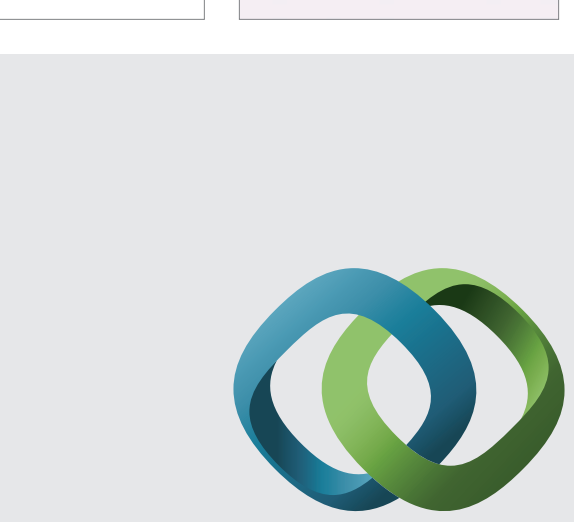

\section{Hindawi}

Submit your manuscripts at

http://www.hindawi.com
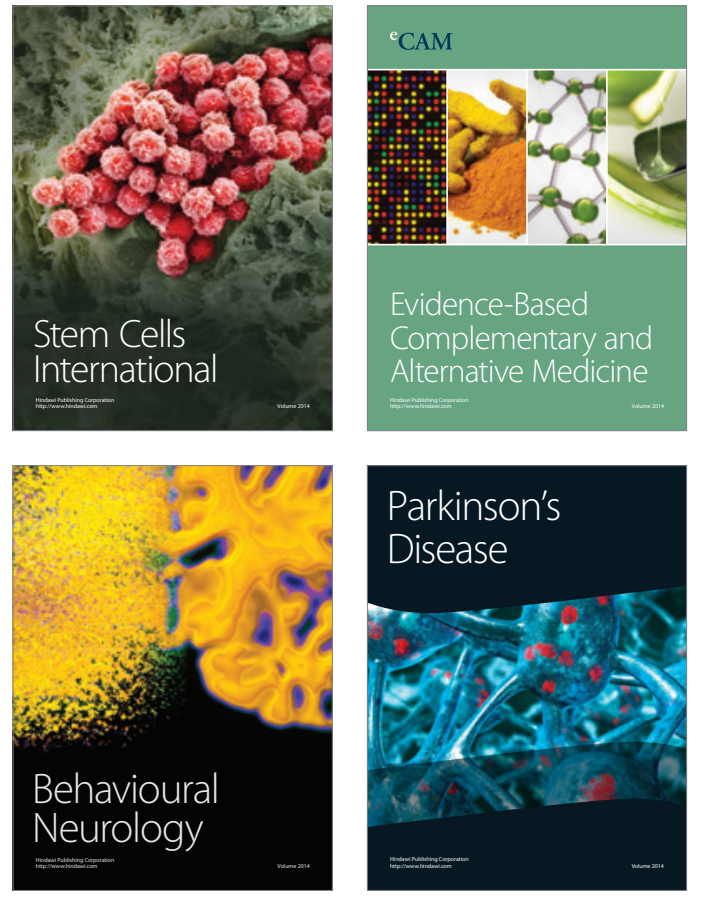
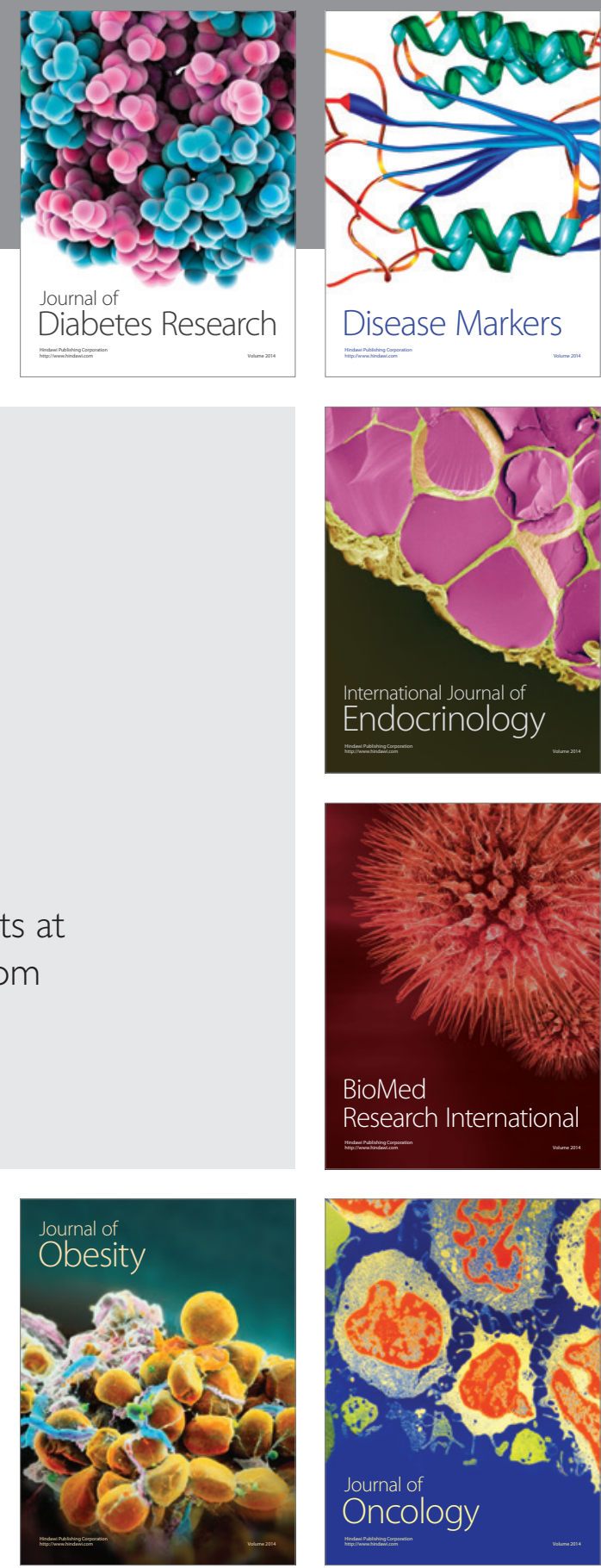

Disease Markers
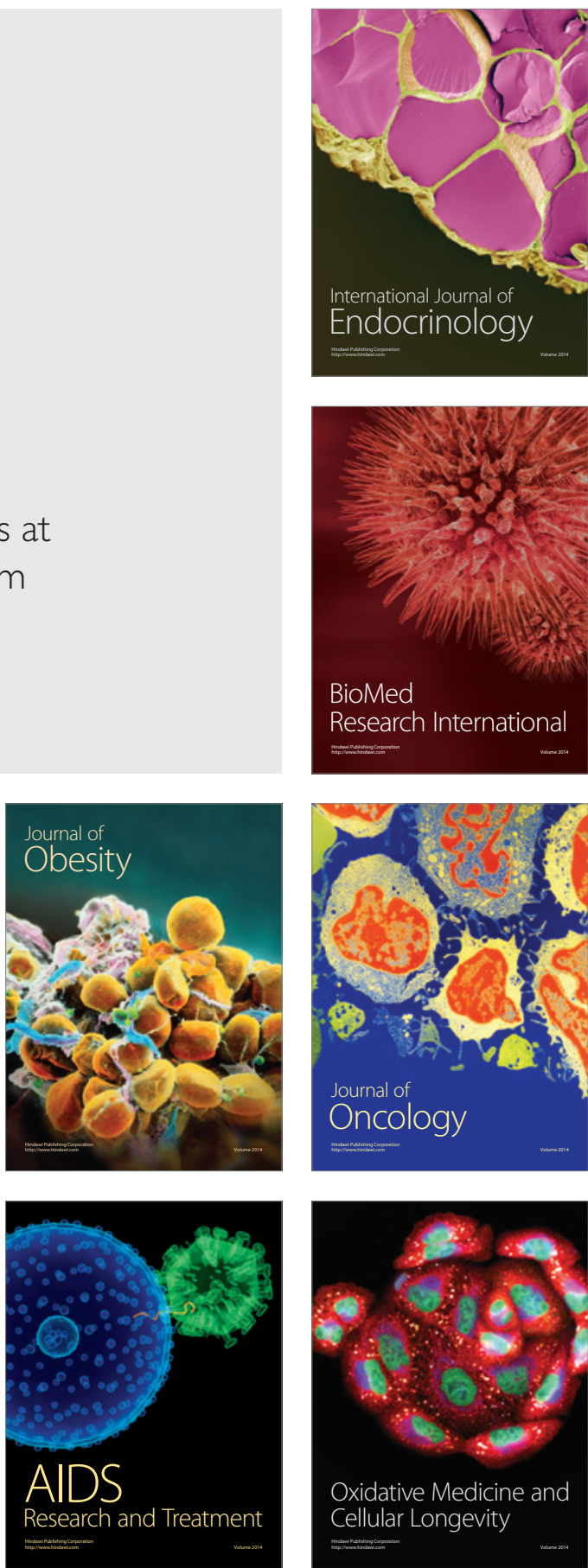